\title{
Comparative efficacy of 5 suture configurations for arthroscopic rotator cuff tear repair: a network meta-analysis
}

Wei Wang ${ }^{1}$, Hui Kang ${ }^{1}$, Hongchuan $\mathrm{Li}^{1}$, Jian $\mathrm{Li}^{1}$, Yibin Meng ${ }^{2}$ and Peng $\mathrm{Li}^{3^{*}}{ }^{\mathrm{C}}$

\begin{abstract}
Background: Rotator cuff tear is one of the most common complaint with shoulder pain, disability, or dysfunction. So far, different arthroscopic techniques including single row (SR), double row (DR), modified Mason-Allen (MMA), suture bridge (SB) and transosseous (TO) have been identified to repair rotator cuff. However, no study has reported the comparative efficacy of these 5 suture configurations. The overall aim of this network meta-analysis was to analyze the clinical outcomes and healing rate with arthroscopy among SR, DR, MMA, SB and TO.

Methods: A systematic literature was searched from PubMed, EBSCO-MEDLINE, Web of Science, google scholar and www.dayi100.com, and checked for the inclusion and exclusion standards. The network meta-analysis was conducted using Review Manager 5.3 and SATA 15.0 software.

Results: Thirty-four studies were eligible for inclusion, including 15 randomized controlled trials, 17 retrospective and 2 prospective cohort studies, with total 3250 shoulders. Two individual reviewers evaluated the quality of the 34 studies, the score form 5 and 9 of 10 were attained according to the Newcastle-Ottawa Scale for the 17 retrospective and 2 prospective studies. There was no significant distinction for the Constant score among 5 groups in the 16 studies with 1381 shoulders. The treatment strategies were ranked as MMA, DR, SB, SR and TO. In ASES score, 14 studies included 1464 shoulders showed that no significant differences was showed among all 5 groups after surgery. Whereas the efficacy probability was TO, MMA, DR, SB and SR according to the cumulative ranking curve. The healing rate in 25 studies include 2023 shoulders was significant in both SR versus DR [risk ratio 0.45 with $95 \%$ credible interval $(0.31,0.65)$ ], and SR versus SB [risk ratio 0.45 (95\% credible interval $0.29,0.69)$ ], and no significant in the other comparison, the ranking probability was MMA, SB, DR, TO and SR.
\end{abstract}

Conclusion: Based on the clinical results, this network meta-analysis revealed that these 5 suture configurations shows no significant difference. Meanwhile, suture bridge may be the optimum treatment strategy which may improve the healing rate postoperatively, whereas the DR is a suboptimal option for arthroscopic rotator cuff repairs.

Keywords: Rotator cuff tears, Arthroscopy, Rotator cuff repair, Single row, Double row, Modified Mason-Allen, Suture bridge

\footnotetext{
*Correspondence: peng96330@outlook.com

${ }^{3}$ Department of Hand Surgery, Honghui Hospital, Xi'an Jiaotong

University, 76 Guo Road, Beilin South District, Xian City 710054, Shanxi Province, China

Full list of author information is available at the end of the article
}

\begin{abstract}
Introduction
Rotator cuff tear is a common problem that impairs the shoulder, and leads to the shoulder pain and poor function, along with insomnia [1]. The incidence of rotator cuff tear increases in people above 30 by $16-34 \%$ [2], and reaches approximately $54 \%$ in people in their 60 s [3]. Only in the USA, the cost for treatment, evaluation,
\end{abstract} original author(s) and the source, provide a link to the Creative Commons licence, and indicate if changes were made. The images or other third party material in this article are included in the article's Creative Commons licence, unless indicated otherwise in a credit line to the material. If material is not included in the article's Creative Commons licence and your intended use is not permitted by statutory regulation or exceeds the permitted use, you will need to obtain permission directly from the copyright holder. To view a copy of this licence, visit http://creativecommons.org/licenses/by/4.0/. The Creative Commons Public Domain Dedication waiver (http://creativeco mmons.org/publicdomain/zero/1.0/) applies to the data made available in this article, unless otherwise stated in a credit line to the data. 


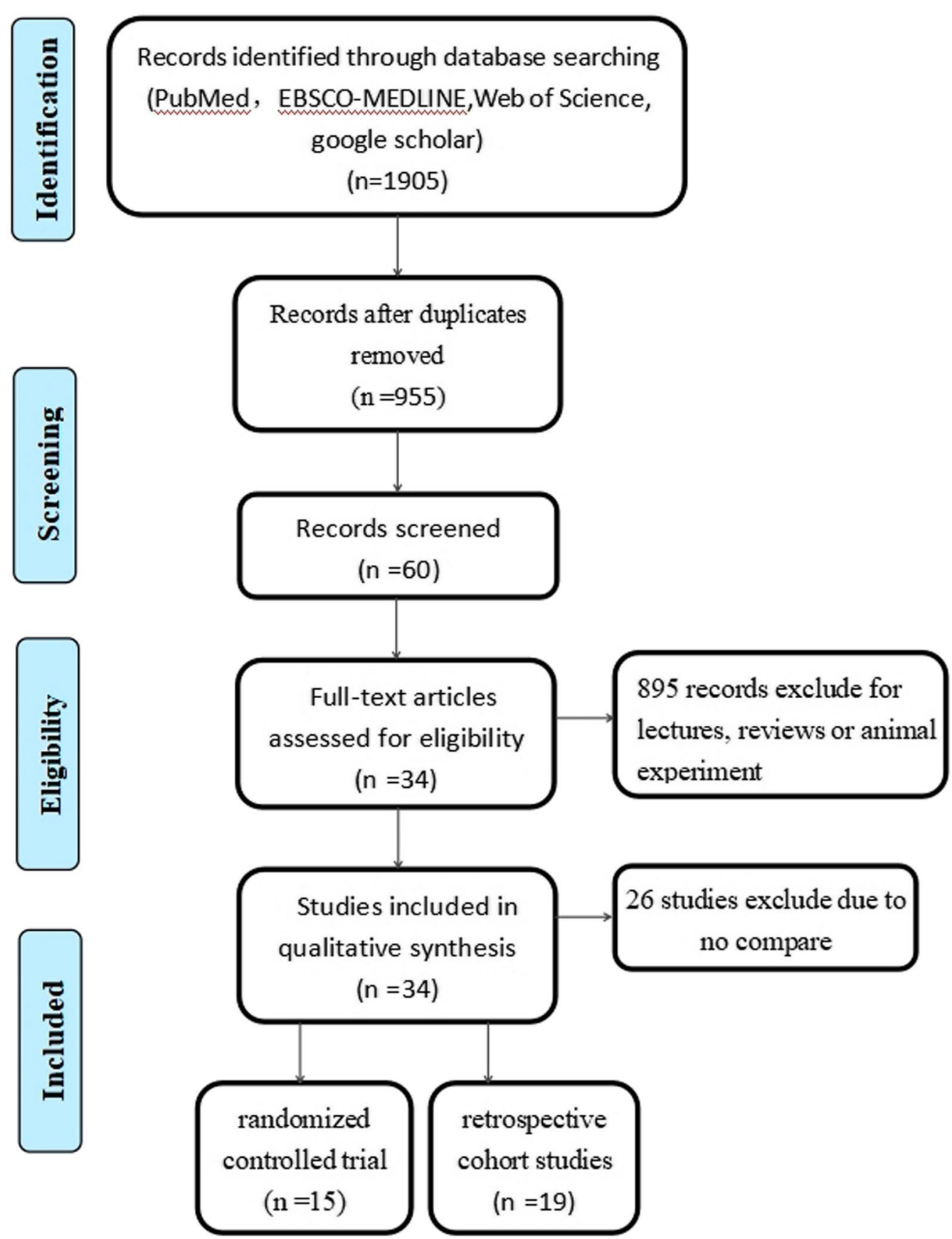

Fig. 1 Search strategy flow diagram

and management to this disease costs 3 billion US dollars, every year [4]. According to the. American Academy of Orthopaedic Surgeons reports that only 16\% of rotator cuff tears had been managed and treated appropriately whereas $31 \%$ "may" have been appropriate, and $53 \%$ were "rarely appropriate" [5]. This situation was still a challenge for rotator cuff tear repair worldwide, with the need to promote functional recovery and increase the healing rate.

In recent years, significant development has been made in both the operative and conventional therapies of shoulder pain and pathological conditions [6]. The surgical remedy should be employed if conventional treatment fails. In arthroscopic rotator cuff repair, different 
Table 1 Basic data of included studies

\begin{tabular}{|c|c|c|c|c|c|c|c|c|c|}
\hline First author & Year & Country & $\begin{array}{l}\text { Evidence } \\
\text { level }\end{array}$ & Interventions & Sample (shoulder) & $\begin{array}{l}\text { Follow-up } \\
\text { (months) }\end{array}$ & Study design & Outcome & Nos \\
\hline Mohamed & 2018 & Egypt & III & MMA versus SB & $21 / 25$ & 49 & $\mathrm{RCT}$ & Constant; ASES & - \\
\hline Michael E & 2018 & Greece & $\|$ & SR versus SB & $34 / 32$ & 46 & $\mathrm{RCS}$ & Constant; healing rate & 7 \\
\hline Christian & 2012 & Germany & III & MMA versus SB & $20 / 20$ & 16 & RCS & Constant; healing rate & 8 \\
\hline Kwang & 2018 & Korea & III & MMA versus $S B$ & $39 / 37$ & 35 & RCS & $\begin{array}{l}\text { Constant; ASES; heal- } \\
\text { ing rate }\end{array}$ & 8 \\
\hline William & 2010 & USA & III & SR versus SB & $78 / 54$ & 24 & PCS & ASES; healing rate & 9 \\
\hline Atsushi & 2017 & Japan & $\|$ & TO versus SB & $11 / 10$ & 6 & $\mathrm{RCT}$ & Constant & - \\
\hline Teruhisa & 2011 & Japan & III & SR versus DR versus SB & $65 / 23 / 107$ & 24 & $\mathrm{RCS}$ & ASES; healing rate & 9 \\
\hline Cosimo & 2013 & Italy & III & SR versus DR & $20 / 20$ & 40 & $\mathrm{RCS}$ & Constant; healing rate & 8 \\
\hline Frank & 2014 & USA & III & SR versus DR versus SB & $20 / 21 / 22$ & 24 & RCS & $\begin{array}{l}\text { Constant; ASES; heal- } \\
\text { ing rate }\end{array}$ & 9 \\
\hline Ignacio & 2012 & Spain & । & SR versus DR & $80 / 80$ & 24 & RCT & $\begin{array}{l}\text { Constant; ASES; heal- } \\
\text { ing rate }\end{array}$ & - \\
\hline Gary M & 2013 & USA & । & SR versus SB & $43 / 47$ & 10 & $\mathrm{RCT}$ & Healing rate & - \\
\hline Ji-Sang & 2019 & Korea & III & SR versus SB & $31 / 25$ & 24 & RCS & $\begin{array}{l}\text { Constant; ASES; heal- } \\
\text { ing rate }\end{array}$ & 7 \\
\hline Burks & 2009 & Australia & I & SR versus DR & $20 / 20$ & 12 & $\mathrm{RCT}$ & ASES & - \\
\hline $\mathrm{Ma}$ & 2011 & China & $\|$ & SR versus DR & $27 / 20$ & 24 & $\mathrm{RCT}$ & $\begin{array}{l}\text { Constant; ASES; heal- } \\
\text { ing rate }\end{array}$ & - \\
\hline Charousset & 2007 & France & $\|$ & SR versus DR & $35 / 31$ & 28 & $\mathrm{RCS}$ & ASES; healing rate & 6 \\
\hline Park & 2008 & Korea & $\|$ & SR versus DR & $40 / 38$ & 24 & RCS & Constant; healing rate & 8 \\
\hline Franceschi & 2007 & Italy & I & SR versus DR & $30 / 30$ & 24 & $\mathrm{RCT}$ & Constant; ASES & - \\
\hline Sugaya & 2005 & Japan & III & SR versus DR & $39 / 41$ & 35 & RCS & Healing rate & 8 \\
\hline Kyoung & 2011 & Korea & I & SR versus DR & $31 / 31$ & 24 & $\mathrm{RCT}$ & ASES; healing rate & - \\
\hline Andrea & 2009 & Italy & I & SR versus DR & $40 / 40$ & 24 & $\mathrm{RCT}$ & $\begin{array}{l}\text { Constant; ASES; heal- } \\
\text { ing rate }\end{array}$ & - \\
\hline Nuri & 2009 & Turkey & $\|$ & SR versus DR & $34 / 34$ & 24 & $\mathrm{RCT}$ & Constant & - \\
\hline Lapner & 2012 & Canada & I & SR versus DR & $39 / 34$ & 24 & $\mathrm{RCT}$ & Constant & - \\
\hline Francesco & 2016 & Italy & I & SR versus DR & $25 / 25$ & 24 & $\mathrm{RCT}$ & $\begin{array}{l}\text { Constant; ASES; heal- } \\
\text { ing rate }\end{array}$ & - \\
\hline Eduard & 2009 & Switzerland & III & SR versus DR & $32 / 33$ & 25 & RCS & Healing rate & 8 \\
\hline Manuel & 2020 & Spain & $\|$ & $S R$ versus $S B$ & $25 / 25$ & 33 & PCS & Constant & 9 \\
\hline Randelli P & 2017 & California & I & TO versus SR & $34 / 35$ & 15 & $\mathrm{RCT}$ & $\begin{array}{l}\text { Constant; ASES; heal- } \\
\text { ing rate }\end{array}$ & - \\
\hline Luís Filipe & 2018 & Brazil & III & SR versus DR & $29 / 27$ & 38 & RCS & $\begin{array}{l}\text { Constant; ASES; heal- } \\
\text { ing rate }\end{array}$ & 8 \\
\hline Jeung & 2017 & Korea & III & SR versus SB & $190 / 225$ & 53 & RCS & ASES & 7 \\
\hline Jong-Hun & 2010 & Korea & III & SR versus DR & $22 / 25$ & 22 & $\mathrm{RCS}$ & $\begin{array}{l}\text { Constant; ASES; heal- } \\
\text { ing rate }\end{array}$ & 8 \\
\hline Roshan & 2017 & India & $\|$ & SR versus DR & $28 / 28$ & 6 & $\mathrm{RCT}$ & ASES; healing rate & - \\
\hline Junji & 2015 & Japan & III & SR versus SB & $25 / 36$ & 81 & RCS & Healing rate & 7 \\
\hline Raffaele & 2018 & Italy & $\|$ & TO versus SR & $54 / 42$ & 24 & RCS & $\begin{array}{l}\text { Constant; ASES; heal- } \\
\text { ing rate }\end{array}$ & 9 \\
\hline Robert Z & 2018 & USA & III & SR versus SB & $22 / 25$ & 12 & RCS & ASES; healing rate & 7 \\
\hline Francisco & 2006 & Spain & । & SR versus DR & $50 / 50$ & 26 & $\mathrm{RCT}$ & Healing rate & - \\
\hline
\end{tabular}

$R C T$ randomized controlled trial, $R C S$ retrospective cohort study, $P C S$ prospective cohort study, SR single-row, DR double-row, SB suture bridge, MMA modified MasonAllen, TO transosseous

suture techniques, with anchors, have been used worldwide, such as single row (SR), double row (DR), modified Mason-Allen (MMA), suture bridge (SB) and transosseous (SO). Even though development had been acquired recently with arthroscopic RCR by techniques of anchors fixation, the outcomes are not satisfactory. 
Random sequence generation (selection bias)

Allocation concealment (selection bias)

Blinding of participants and personnel (performance bias)

Blinding of outcome assessment (detection bias)
Incomplete outcome data (attrition bias)
Selective reporting (reporting bias)
Other bias

Blinding of outcome assessment (detection bias)
Incomplete outcome data (attrition bias)
Selective reporting (reporting bias)
Other bias

Blinding of outcome assessment (detection bias)
Incomplete outcome data (attrition bias)
Selective reporting (reporting bias)
Other bias

Blinding of outcome assessment (detection bias)
Incomplete outcome data (attrition bias)
Selective reporting (reporting bias)
Other bias

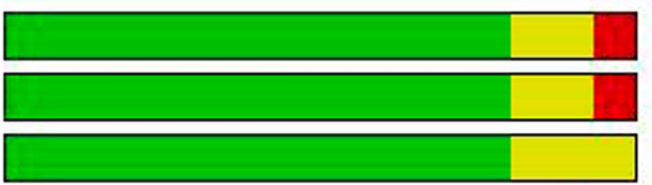

$\square$

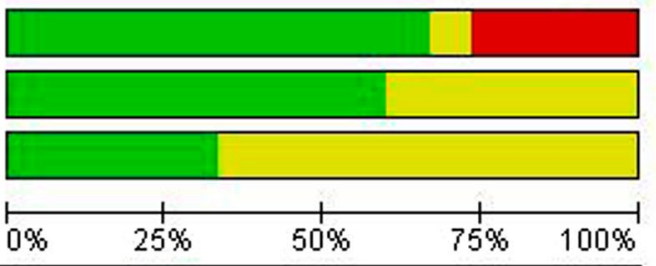

Low risk of bias

Unclear risk of bias

High risk of bias

Fig. 2 Risk of bias graph: review authors'judgements about each risk of bias item presented as percentages across all included RCTs

Therefore, the innovations in the methods for rotator cuff repair (RCR) are necessary. In clinical practice, surgeons had many choices based on personal experience, and the best treatment choice varies patient to patient. So far, no study has shown the comparative efficacy of different suture techniques, including SR, DR, MMA, SB and TO, used during arthroscopic RCR.

It is critical to evaluate the comparative efficacy, directly and indirectly, with the existing data using network meta-analysis, and summarize and explain the broader evidence to understand the advantages of different suture techniques. Our purpose was to prove which application in arthroscopic RCR would improve the shoulder function and tendon healing better. Therefore, this study aimed to perform the network meta-analysis for the currently available functional results and healing rate of arthroscopic RCR with SR, DR, MMA, SB and TO.

\section{Methods}

\section{Search procedure}

This network meta-analysis was conducted based on the Preferred Reporting Items for Systematic Reviews and Meta-Analysis guidelines. PubMed, EBSCO-MEDLINE, Web of Science, google scholar and www.dayi100.com were searched for articles published from January 2000 to March 2020 with the following words: "rotator cuff tears; arthroscopy; rotator cuff repair (RCR); single row (SR); double row (DR); modified Mason-Allen (MMA); suture bridge (SB); transosseous (TO)". From PubMed, we used the search strategies "rotator cuff tears" AND "single row" OR "double row" OR "modified Mason-Allen" OR "suture bridge" OR "transosseous" assembled with all included literature.

\section{Inclusion criteria}

The inclusion criteria included: (1) patients diagnosed with rotator cuff injury and repaired with arthroscopy; (2) the control group was any suture configurations of 5 , they were compared between two groups respectively. (3) the studies included clinical functional outcomes and healing rate for all groups, with outcomes in accordance with Constant score system, the American shoulder or elbow surgeons score system (ASES). (4) clinical followup at least 6 months; (5) randomized controlled trial (RCT), prospective or retrospective cohort studies.

\section{Exclusion criteria}

Case report, animal experiments, and basic medicine studies were excluded. Patients who underwent shoulder surgery were also excluded.

\section{Data extraction and quality assessment}

The title and abstracts of all the searched literatures were accessed, the duplicates and animal trials were removed.

(See figure on next page.)

Fig. 3 a-c The forest plot of conventional meta-analysis for Constant score; $\mathbf{d}$ network plot of suture configurations comparisons for Constant score. The size of the blue area indicates the sample size of each group, and the thickness indicates the studies of comparisons between two groups; e the predictive interval plot for Constant score; $\mathbf{f}$ head-to-head comparisons of network meta-analysis for Constant score; $\mathbf{g}$ the SURCA show the treatment efficacy of each suture configurations for Constant score. MMA modified Mason-Allen, SB suture bridge, SR single-row, DR double-row, TO transosseous 


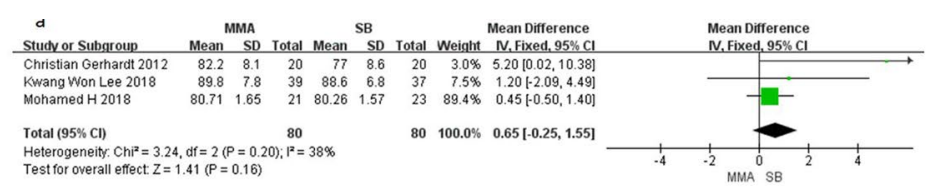

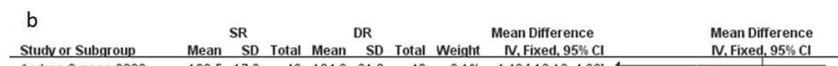

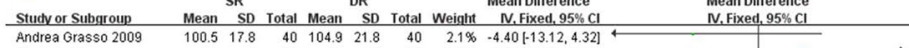

Total (95\% Cl) $\quad 322 \quad 317 \quad 100.0 \% \quad-1.20[-2.46,0.06]$

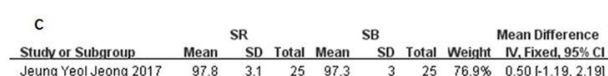

Total (95\% Cl) $\quad 215 \quad 250 \quad 100.0 \% \quad 0.71[-0.78,2.19]$

Test tor overall effiect. $Z=0.93(P=0.35$

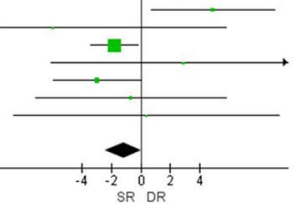

d
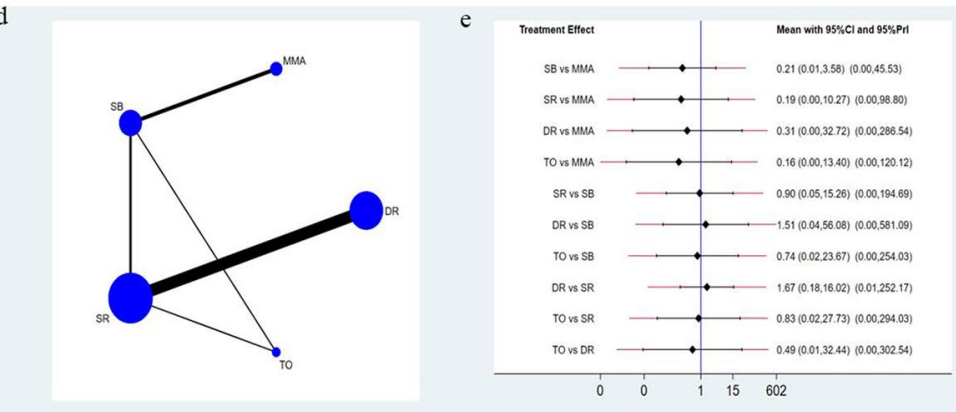

f
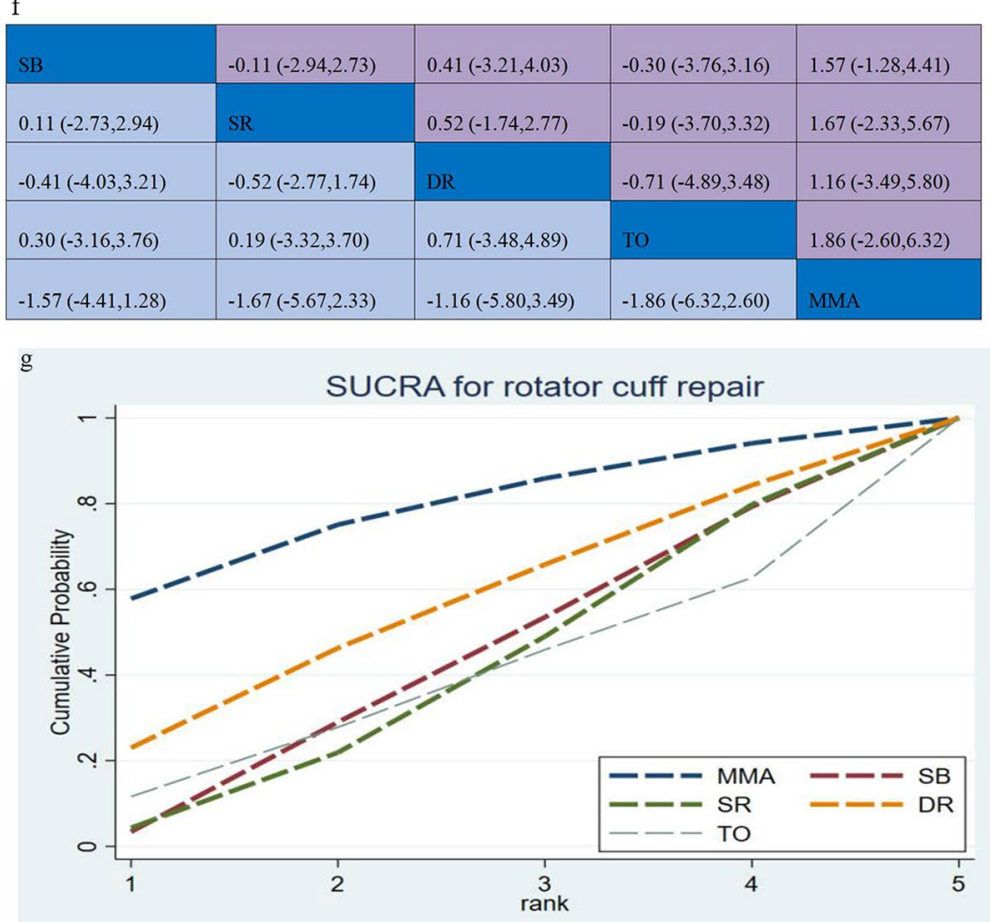

Fig. 3 (See legend on previous page.) 
Time of publication, study type, first author, patient information, surgical technique, clinical outcomes, and healing rate was listed into the standard form to compare. All of them were extracted by two independent authors (Peng Li and Hui Kang). Another author (Yibin Meng) crosschecked all the included and excluded studies for any discrepant opinion.

The quality of randomized controlled trials (RCT) was evaluated with Collaboration tool [7]. The judgment standard included six indexes: sequence generation, allocation hiding, blindness, incomplete result data, selective result reporting, and other "bias", "low risk", "high risk", or "unclear" were the grading standard for each index of the included studies. According to the Newcastle-Ottawa Scale (NOS) [8], the quality of prospective and retrospective cohort studies was evaluated. The two authors (Hongchuan $\mathrm{Li}$ and Jian $\mathrm{Li}$ ) independently assessed the quality of these literatures.

\section{Data analysis}

Revman 5.3 software was employed for all conventional meta-analysis. The weighted mean difference (MD) and standard deviation (SD) were used to analyze the continuous variables (Constant, ASES), and relative risk was used to appraise the dichotomous variables (healing rate). Values were considered as statistically significant when $P$ value $<0.05$, including $95 \%$ CI. The $I^{2}$ statistical was selected to test the heterogeneity of included studies (significance, $I^{2}>50 \%$ ). For the pool outcomes of comparable studies, $I^{2}>50 \%$ was considered the significant heterogeneity and belong to the random-effect model. The network meta-analysis was based on a frequent framework with indirect and direct comparing. Stata software (version 15.0) was used to perform network, forest, and predictive interval plots $[9,10]$. The rank of the five suture configurations for arthroscopic repair in the aspect of shoulder function and healing rate was assessed with the SUCRA [11]. The surface indicates the treatment efficacy, and the more surface shows, the better result. The inconsistencies were estimated with network side-split. The publication bias was judged with the funnel plot.

\section{Result}

\section{Study identification and assessment}

One thousand ninety-five studies were identified, studies not fulfilling the inclusion criteria were excluded.
Ultimately, 34 studies [12-45] fulfilled the inclusion criteria and the assessment in this network meta-analysis (Fig. 1). These studied include 15 RCTs [12, 17, 21, 22, $24,25,28,30-34,37,41,45], 2$ prospective [16, 36] and 17 retrospective cohort studies [13-15, 18-20, 23, 26, $27,29,35,38-40,42-44]$, with a total of 3250 shoulders (Table 1).

\section{Characteristics and quality assessments}

Table 1 shows the characteristics of the selected studies. The quality of 15 RCTs was assessed by two authors independently using the Cochrane Handbook for Systematic Reviews of Interventions 5.0 (Fig. 1). Furthermore, the NOS was applied to assess the pool bias of 2 prospective and 17 retrospective cohort studies (Fig. 2) to attain the score form 5 and 9 of 10.

\section{Constant score}

Sixteen studies $[12,14,15,17,19-21,24,27,30,31$, $33,35,36,39,43]$, including 1381 shoulders assess, the clinical functions using Constant score, showed postoperatively difference between two groups in this network meta-analysis. The conventional meta-analysis is presented in Fig. 3a-c (MD with 95\% CI). The network plot between the five techniques, and the network metaanalysis is shown in Fig. 3d-g. In Constant score, direct and indirect comparison by conventional and network meta-analysis illustrated no significant differences among SR, DR, SB, MMA, and TO (Fig. 3e, f). According to the SUCRA (Fig. 3g), the ranking probability of the treatment efficacy of each suture configuration for Constant score was MMA, DR, SB, SR, and TO.

\section{ASES score}

Regarding the ASES score, 14 studies [12, 15, 20, 21, 23$25,27,29,30,33,39,41,43]$, including 1464 shoulders assess, the clinical function between the different two groups postoperatively in this network meta-analysis. The conventional meta-analysis is shown in Fig. 4a-c (MD with 95\% CI). The network plot between the five techniques and network meta-analysis is shown in Fig. $4 \mathrm{~d}-\mathrm{g}$. In the ASES score, it was no significant between any two sutures configurations in the 14 studies (Fig. 4e, f) with direct and indirect comparison by both conventional and network meta-analysis. On the basis of the SUCRA (Fig. $4 \mathrm{~g}$ ), the ranking probability of the treatment efficacy

(See figure on next page.)

Fig. 4 a-c The forest plot of conventional meta-analysis for ASES score; $\mathbf{d}$ network plot of suture configurations comparisons for ASES score. The size of the blue area indicates the sample size of each group, and the thickness indicates the studies of comparisons between two groups; e the predictive interval plot for ASES score; $\mathbf{f}$ head-to-head comparisons of network meta-analysis for ASES score; $\mathbf{g}$ the SURCA show the treatment efficacy of each suture configurations for ASES score. MMA modified Mason-Allen, SB suture bridge, SR single-row, DR double-row, TO transosseous 


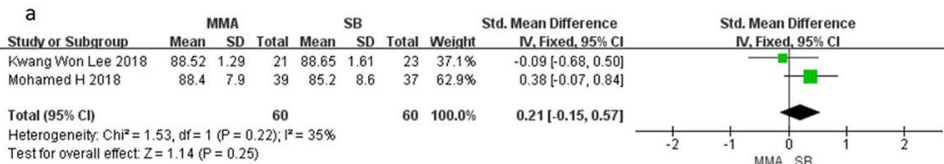
Test tor overall effect $Z=1.14(P=0.25)$

MMA SB

b

$\begin{array}{ccccc}\text { b } & \text { SR } & \text { DR } & \text { Std. Mean Difference } \\ \text { Studv or Subgroup } & \text { Mean SD total Mean } & \text { SD Total Weight } & \text { N. Fixed, 95\% CI }\end{array}$

$\begin{array}{ccccc}\text { b } & \text { SR } & \text { DR } & \text { Std. Mean Difference } \\ \text { Studvor Subgroup } & \text { Mean SD total Mean } & \text { SD Total Weight } & \text { N. Fixed, 95\% Cl }\end{array}$ \begin{tabular}{lrrrrrrrr}
\hline Frank 2014 & 83 & 21.4 & 20 & 87 & 12.4 & 21 & $6.4 \%$ & $-0.23+0.84,0.39$ \\
Ignacio Carbonel 2012 & 80.3 & 6.2 & 80 & 80.3 & 6.2 & 80 & $25.2 \%$ & $0.00-0.31,0.31]$
\end{tabular} $\begin{array}{llllllllll}\text { Kyoung Hwan Koh } 2011 & 85.9 & 15.2 & 31 & 82.5 & 21.9 & 31 & 9.7 \% & 0.18-0.32 .0681\end{array}$

Ma 2011

Park 2008

Peter L.C. Lapner 2012

Roshan Wade 2017

$\begin{array}{rrrrrrr}91.25 & 2.36 & 27 & 91.38 & 21.36 & 26 & 8.3 \% \\ 91.6 & 4.48 & 40 & 92.97 & 227 & 38 & 120 \%\end{array}$

$\begin{array}{lllllll}91.6 & 4.48 & 40 & 92.97 & 2.27 & 38 & 12.05\end{array}$

$\begin{array}{rrrrrrr}85.9 & 14 & 20 & 85.5 & 20 & 20 & 6.3 \%\end{array}$

Sugava 2005

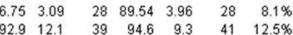

Total $(95 \% \mathrm{Cl})$

24

$319 \quad 100.0 \%$

$-0.05+0.59,0.48$

$-0.38+-0.83,0.07]$

$-0.08+0.54,0.38]$
$0.02[0.060,0.64]$

$-0.77[-1.32,-0.23]$

$-0.16[-0.60,0.28]$

Heterogeneity: Chi $\mathrm{F}^{2}=9.16, \mathrm{df}=8(P=0.33) ; P^{2}=13 \%$
Test for overall effect $Z=1.74(P=0.08)$

$-0.14[-0.29,0.02]$

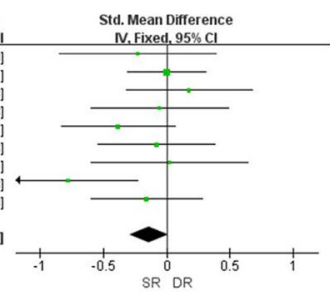

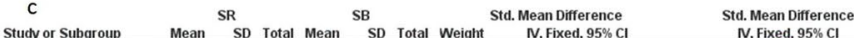

$\begin{array}{lllllllll}\text { Jeung Yeol Jeong } 2017 & 79.91 & 17.52 & 190 & 81.41 & 18.11 & 225 & 88.2 \% & -0.0850 .28,0.11\end{array}$

$\begin{array}{lrrrrrrrr}\text { Jisang Yoon } 2019 & 91 & 8.4 & 31 & 91.4 & 8.7 & 25 & 11.8 \% & -0.05[-0.057,0.48]\end{array}$

Iotal (95\% Cl)

221

$250 \quad 100.0 \%$

$-0.08[-0.26,0.10]$

Heterogeneity: Chi ${ }^{2}=0.02$, df $=1(P=0.90) ; 1^{2}=0$
Test for owerall effect: $Z=0.86(P=0.39)$

IV. Fixed, $95 \% \mathrm{CI}$

d

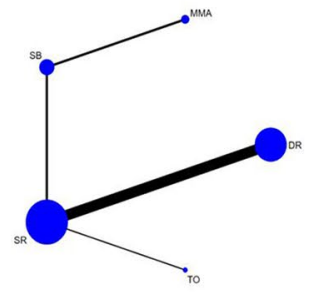

e

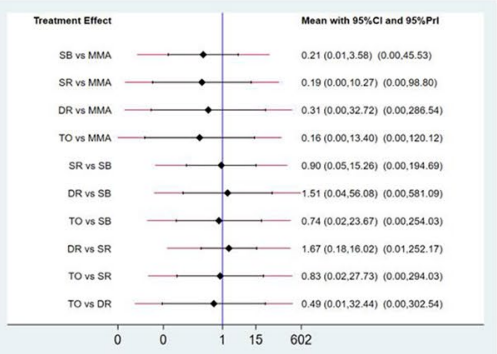

f

\begin{tabular}{|l|l|l|l|l|}
\hline SB & $-1.07(-4.07,1.93)$ & $-0.07(-3.26,3.13)$ & $1.43(-2.59,5.45)$ & $0.46(-1.45,2.37)$ \\
\hline $1.07(-1.93,4.07)$ & SR & $1.01(-0.11,2.12)$ & $2.50(-0.18,5.19)$ & $1.53(-2.01,5.07)$ \\
\hline $0.07(-3.13,3.26)$ & $-1.01(-2.12,0.11)$ & DR & $1.49(-1.41,4.40)$ & $0.53(-3.17,4.22)$ \\
\hline$-1.43(-5.45,2.59)$ & $-2.50(-5.19,0.18)$ & $-1.49(-4.40,1.41)$ & TO & $-0.97(-5.41,3.47)$ \\
\hline$-0.46(-2.37,1.45)$ & $-1.53(-5.07,2.01)$ & $-0.53(-4.22,3.17)$ & $0.97(-3.47,5.41)$ & MMA \\
\hline
\end{tabular}

g

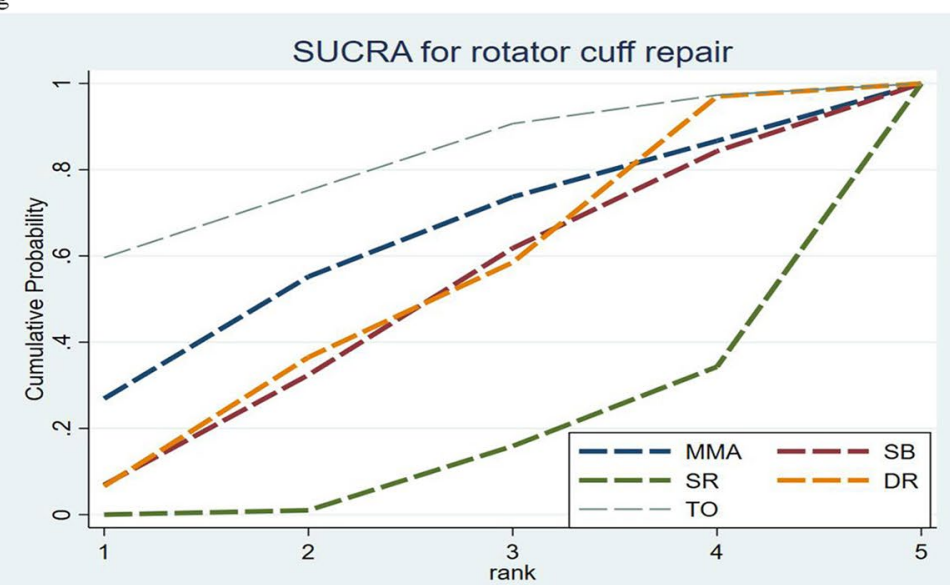

Fig. 4 (See legend on previous page.) 
of each suture configuration for ASES score was TO, MMA, DR, SB and SR.

\section{Healing rate}

Twenty-five studies [13-16, 18-22, 24-26, 28-30, 33, 34, 36, 37, 39, 41-45], including 2023 shoulders assess, the healing rate between differentiate two groups postoperatively in this network meta-analysis. The conventional meta-analysis is presented in Fig. 5a-d (RR with 95\% CI). The network plot between the 5 techniques and network meta-analysis is shown in Fig. 5e-h. Regarding the healing rate, there was significant differences both SR versus DR and SR versus SB in the network meta-analysis (Fig. 5g), and no significant in the other comparison (Fig. 5f, g). Judging from the SUCRA (Fig. 5h), the ranking probability of the treatment efficacy of each method for healing rate was MMA, SB, DR, TO and SR.

\section{Inconsistency and bias of publication analysis}

The outcomes of pair-wise meta-analysis and the network meta-analysis matched significantly. In the study, there was no inconsistency for each result between the direct and indirect comparison (Table 2). Moreover, no visual evidence of bias of publication for each outcome was demonstrated from the funnel plots (Fig. 6), and it was similarly balanced on both sides of the funnel.

\section{Discussion}

The network meta-analysis revealed the comparative efficacy of 5 suture configurations for rotator cuff tear in terms of the Constant score, ASES score, and healing rate for patients who underwent arthroscopic repair with MMA, SB, SR, DR, and TO. This study showed the following: (1) there was no significant differences among the five suture configurations in term of Constant score, and the overall ranking was MMA, DR, SB, SR, and TO; (2) there was no significant difference in ASES score, and the overall ranking was TO, MMA, DR, SB, and SR. (3) SR leading to a lower healing rate than $\mathrm{DR}$ and $\mathrm{SB}$, and the ranking for healing rate was MMA, SB, DR, TO, and SR.

The constant score is a critical criterion for shoulder treatment including shoulder function, range of motion, pain and strength [46]. Gerhardt et al. [14] found that clinical results after MMA and SB techniques do not demonstrate significant differences in a matched patient cohort. Moreover, Hantes et al. [13] and his co-worker found no difference in Constant scores between the SR and DR techniques in a 46 months follow-up study having 66 patients. Furthermore, Garofalo et al. [43] reported that MMA repair provides comparable clinical results to SR repair in Constant score with arthroscopy. Zafra et al. [36] suggested that there were no differences in Constant score between SR and SB techniques. The network metaanalysis compared the difference among the 5 techniques combined direct and indirect evidences for rotator cuff repair with quantitative way, which illustrated no significant difference among 5 suture configurations. The SUCRA was used to assess the slight differences among MMA, SB, SR, DR and TO. In order to achieve better Constant score, the techniques can be arranged as follows: MMA, DR, SB, SR and TO.

The ASES score is essential for evaluating the therapeutic effect of these five arthroscopic techniques. No difference among the MMA, SB, SR, DR, and TO has been analyzed by the previous evidence-based study. Khalil et al. [12] previously reported that MMA provides comparable functional results to the $\mathrm{SB}$ repair technique. McCormick et al. [20] considered that using SR, DR, or SB techniques, yielded a clinical improvement and revealed no statistically significant difference for ASES score. Garofalo et al. [43] reported no statistically significant difference between SR and TO for the rotator cuff repair in the comparative analysis of ASES scores. No significant differences among MMA, SB, SR, DR and TO repair was found in terms of ASES score from this network meta-analysis. Furthermore, TO technique provided a greater ASES score than MMA, DR, SB and SR techniques according to the SUCRA.

As we all know that the critical point of RCT requires the repaired site tend-to-bone surface healing [47, 48]. One of the most common reasons for the failure of an RCR is the retear because of nonhealing of the primary repair [49]. A study by Park et al. [27] showed that approximately $50 \%$ of repaired rotator cuffs do not heal completely, though the surgical techniques were used. Hantes et al. [13] found that significant superior healing rate was potentially provided with the DR rather than the SR technique, which may due to the contact surface of tendon and bone. So Franceschi et al. [34] suggested that in selected patients with required accelerated postoperative rehabilitation, double-row repair lowered the risk of retear, while maintaining a low rate of stiffness.

(See figure on next page.)

Fig. 5 a-d The forest plot of conventional meta-analysis for healing rate; e network plot of suture configurations comparisons for healing rate. The size of the blue area indicates the sample size of each group, and the thickness indicates the studies of comparisons between two groups; $\mathbf{f}$ the predictive interval plot for healing rate; $\mathbf{g}$ head-to-head comparisons of network meta-analysis for healing rate; $\mathbf{h}$ the SURCA show the treatment efficacy of each suture configurations for healing rate. MMA modified Mason-Allen, SB suture bridge, SR single-row, DR double-row, TO transosseous 

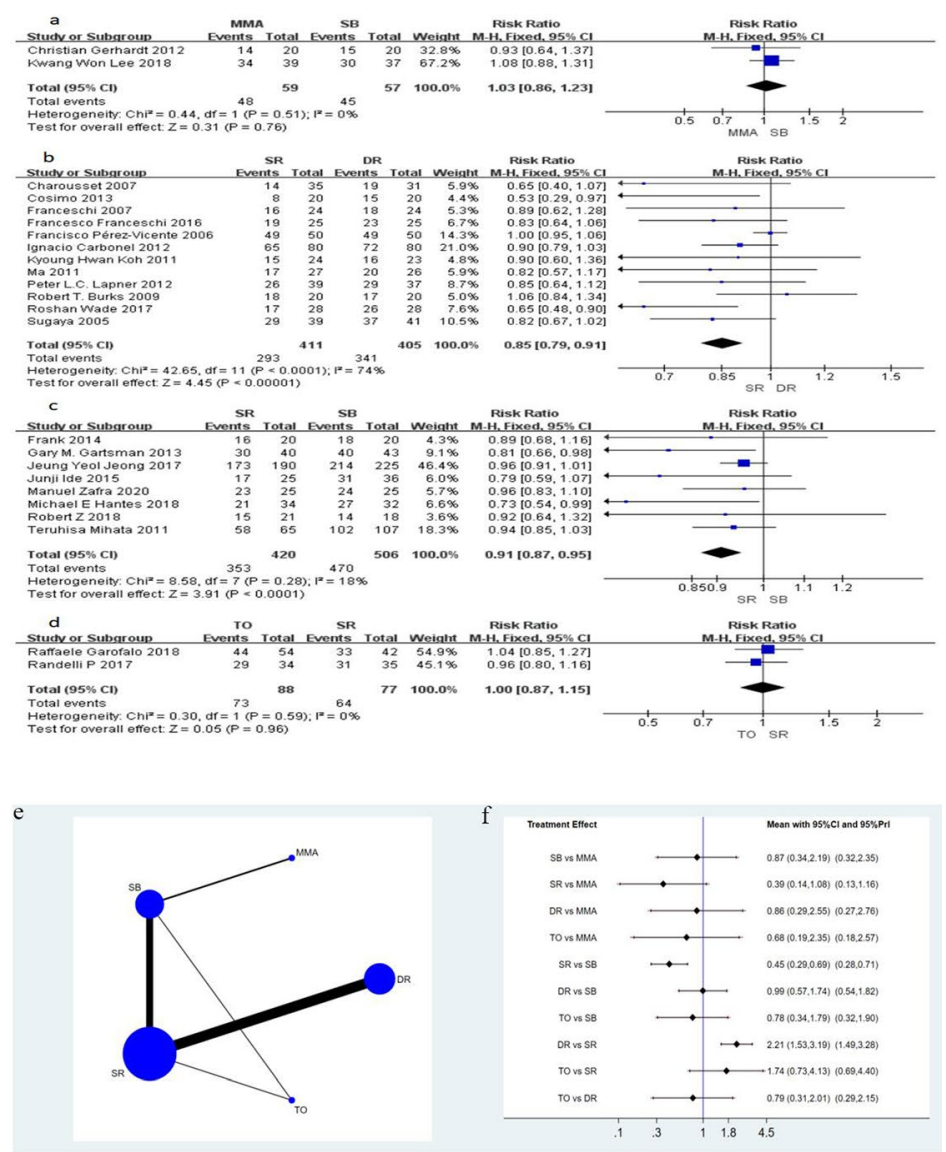

$\mathrm{g}$
\begin{tabular}{|l|l|l|l|l|}
\hline SB & $0.45(0.29,0.69)$ & $0.99(0.57,1.74)$ & $0.78(0.34,1.79)$ & $1.15(0.46,2.92)$ \\
\hline $2.23(1.45,3.41)$ & SR & $2.21(1.53,3.19)$ & $1.74(0.73,4.13)$ & $2.57(0.92,7.15)$ \\
\hline $1.01(0.57,1.77)$ & $0.45(0.31,0.65)$ & DR & $0.79(0.31,2.01)$ & $1.16(0.39,3.44)$ \\
\hline $1.28(0.56,2.95)$ & $0.58(0.24,1.37)$ & $1.27(0.50,3.26)$ & TO & $1.48(0.43,5.15)$ \\
\hline $0.87(0.34,2.19)$ & $0.39(0.14,1.08)$ & $0.86(0.29,2.55)$ & $0.68(0.19,2.35)$ & MMA \\
\hline
\end{tabular}

$\mathrm{h}$

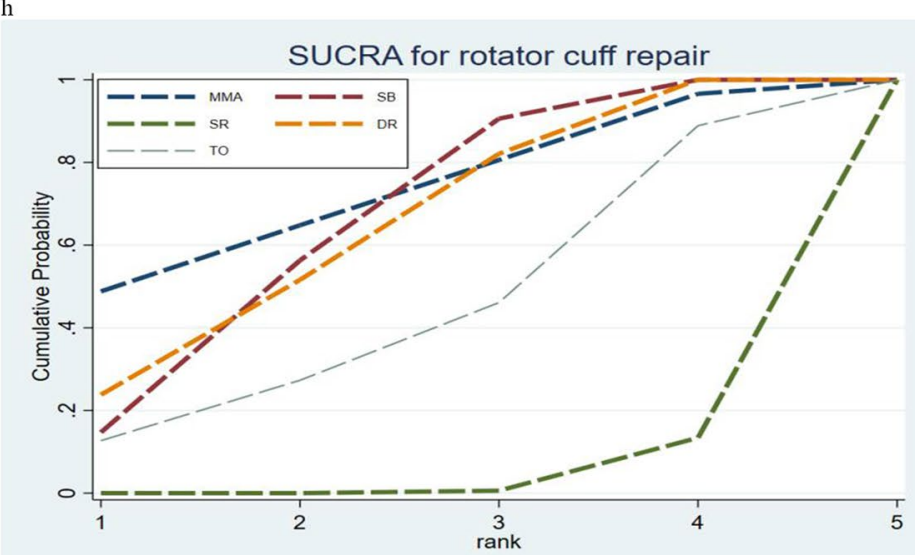

Fig. 5 (See legend on previous page.) 
Table 2 Direct and indirect analysis for inconsistency of network meta-analysis

\begin{tabular}{|c|c|c|c|c|c|c|c|c|}
\hline \multirow[t]{2}{*}{ Outcome } & \multirow[t]{2}{*}{ Comparison } & \multicolumn{2}{|l|}{ Direct } & \multicolumn{2}{|c|}{ Indirect } & \multicolumn{2}{|c|}{ Difference } & \multirow[t]{2}{*}{$P>|z|$} \\
\hline & & Coef. & Std.Err. & Coef. & Std.Err. & Coef. & Std.Err. & \\
\hline \multirow[t]{5}{*}{ Constant score } & MMA versus SB & -1.57 & -1.45 & 0.14 & 27.77 & -1.71 & 27.80 & 0.95 \\
\hline & SB versus SR & 0.85 & 1.41 & -4.05 & 2.85 & 4.90 & 3.18 & 0.12 \\
\hline & SB versus TO & -2.20 & 1.96 & 2.75 & 2.52 & -4.95 & 3.20 & 0.12 \\
\hline & SR versus DR & 0.51 & 1.15 & 3.87 & 66.81 & -3.36 & 66.81 & 0.96 \\
\hline & SR versus TO & 1.90 & 2.08 & -3.05 & 2.41 & 4.95 & 3.20 & 0.12 \\
\hline \multirow[t]{4}{*}{ ASES sore } & MMA versus SB & -0.46 & 0.98 & 0.89 & 28.90 & -1.36 & 28.91 & 0.963 \\
\hline & SB versus SR & -1.07 & 1.53 & 0.43 & 30.88 & -1.51 & 30.91 & 0.96 \\
\hline & SR versus DR & 1.00 & 0.57 & 4.08 & 66.76 & -3.07 & 66.76 & 0.96 \\
\hline & SR versus TO & 2.5 & 1.37 & 5.56 & 20.02 & -3.06 & 20.0 & 0.99 \\
\hline \multirow[t]{5}{*}{ Healing rate } & MMA versus SB & -0.14 & 0.47 & 0.47 & 21.32 & -0.62 & 21.33 & 0.98 \\
\hline & SB versus SR & -0.88 & 0.22 & 0.47 & 0.88 & -1.35 & 0.91 & 0.14 \\
\hline & SB versus TO & 0.18 & 0.51 & -1.17 & 0.75 & 1.36 & 0.91 & 0.14 \\
\hline & SR versus DR & 0.79 & 0.19 & 2.68 & 57.77 & -1.89 & 57.77 & 0.97 \\
\hline & SR versus TO & -0.29 & 0.73 & 1.07 & 0.56 & -1.36 & 0.91 & 0.14 \\
\hline
\end{tabular}

MMA modified Mason-Allen, SB suture bridge, SR single-row, DR double-row, TO transosseous
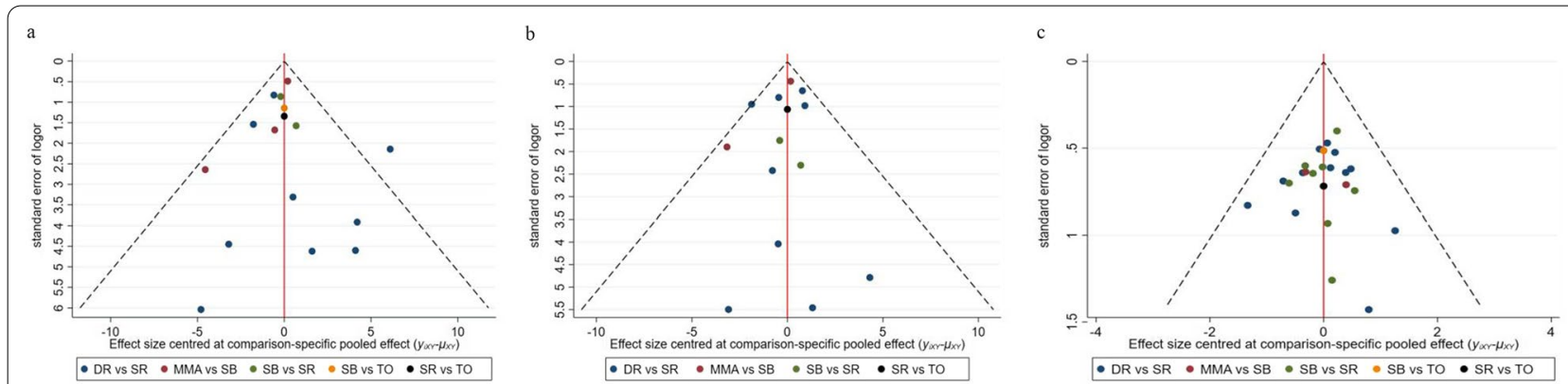

Fig. 6 a The funnel plots of the included studies for constant score. $\mathbf{b}$ The funnel plots of the included studies for ASES score. c The funnel plots of the included studies for healing rate. MMA modified Mason-Allen, SB suture bridge, SR single-row, DR double-row, TO transosseous

Tudisco et al. [19] reported that the healing rates after arthroscopic rotator cuff repair were $89.2 \%$ and $95.3 \%$, respectively, for the SR and SB techniques, which was statistically significant. According to the SUCRA, the treatments efficacy was ranked as MMA, SB, DR, TO and SR repair based on their healing rate.

Our study has several advantages. Firstly, except for only direct groups compare, this network meta-analysis assesses five treatments simultaneously indirectly. As to our knowledge, this is the first time of comparison of MMA, SB, SR, DR, and TO techniques for arthroscopic rotator cuff repair. We compared the five different methods and supplied the SUCRA indirectly with a frequentist framework for network meta-analysis when no headto-head compare existed by combining directly $[50,51]$. Secondly, we avoided selection bias by synthesizing much more studies rather than a conventional meta-analysis. Additionally, this study could gain more precise effect assessments for the five techniques with an updated statistical approach of network meta-analysis.

However, there are also some limitations of the network meta-analysis: (1) some low-quality RCTs and two prospective and 17 retrospective cohort studies, which may impair the significance of the conclusions, but according to the NOS, the mostly score were more than 7. (2) The outcomes were incomplete in some included studies, imputed data were used in the analysis, as we used the same imputation method for the same treatment, the outcomes should still supply effective evaluation. (3) We did not perform a meta-analysis on tear size because the results were reported rarely in 2 studies. In our study, we compared the overall treatment efficacy for all types of rotator cuff repair. (4) Some potential publication biases in the study, it was similarly balanced on both sides of the funnel and demonstrated no visual evidence of publication bias for each result. 


\section{Conclusion}

Our network meta-analysis revealed that no significant difference was found for the functional outcomes among the five suture configurations. SB repairs might be the optimum treatment and improve the healing rate postoperatively. Meanwhile, the DR is a suboptimal option for arthroscopic rotator cuff repairs, which may help and guide clinicians on the appropriate operative program.

\section{Acknowledgements}

The authors thank Dr. Hui Kang, Department of Shoulder and Elbow of Sports Medicine, Honghui Hospital, Xi'an Jiaotong University, for contributing to study concept and design. All authors revised the final manuscript of the paper.

\section{Authors' contributions}

WW designed the research study. HK performed the research. HL provided help and advice on the experiments. JL and YM analyzed the data. WW and $\mathrm{PL}$ wrote the manuscript. All authors contributed to editorial changes in the manuscript. All authors read and approved the final manuscript.

\section{Funding}

Not applicable.

\section{Availability of data and materials}

All data generated or analyzed during this study are included in this published article.

\section{Declarations}

\section{Ethics approval and consent to participate}

Our study did not require an ethical board approval because it did not contain human or animal trials.

\section{Competing interests}

The authors do not have any research foundations, and have not received any economical payments or other conflicts of interest with this study.

\section{Author details}

'Department of Shoulder and Elbow of Sports Medicine, Honghui Hospital, Xi'an Jiaotong University, Xian City 710054, Shanxi Province, China. ${ }^{2}$ Departments of Spine Surgery, Honghui Hospital, Xi'an Jiaotong University, Xian City 710054, Shanxi Province, China. ${ }^{3}$ Department of Hand Surgery, Honghui Hospital, Xi'an Jiaotong University, 76 Guo Road, Beilin South District, Xian City 710054, Shanxi Province, China.

Received: 26 August 2021 Accepted: 15 November 2021 Published online: 11 December 2021

\section{References}

1. Zhang Z, Gu B, Zhu W, Zhu L, Li Q. Arthroscopic versus mini-open rotator cuff repair: a prospective, randomized study with 24-month follow-up. Eur J Orthop Surg Traumatol Orthop Traumatol. 2014;24(6):845-50.

2. Via AG, De Cupis M, Spoliti M, Oliva F. Clinical and biological aspects of rotator cuff tears. Muscles Ligaments Tendons J. 2013;3(2):70-9.

3. Habermeyer P, Krieter C, Tang KL, Lichtenberg S, Magosch P. A new arthroscopic classification of articular-sided supraspinatus footprint lesions: a prospective comparison with Snyder's and Ellman's classification. J Shoulder Elbow Surg. 2008;17(6):909-13.

4. Aurora A, McCarron J, lannotti JP, Derwin K. Commercially available extracellular matrix materials for rotator cuff repairs: state of the art and future trends. J Shoulder Elbow Surg. 2007;16(5 Suppl):S171-8.

5. Cowan JB, Bedi A, Carpenter JE, Robbins CB, Gagnier JJ, Miller BS. Evaluation of American Academy of Orthopaedic Surgeons appropriate use criteria for the management of full-thickness rotator cuff tears. J Shoulder Elbow Surg. 2016;25(7):1100-6.

6. Pogorzelski J, Godin JA, Fritz EM, Cinque ME, Chahla J, Huard J, et al. The use of biological approaches in the treatment of shoulder pathology: a critical analysis review. JBJS Rev. 2017;5(9):e5.

7. Cumpston M, LiT, Page MJ, Chandler J, Welch VA, Higgins JP, et al. Updated guidance for trusted systematic reviews: a new edition of the Cochrane handbook for systematic reviews of interventions. Cochrane Database Syst Rev. 2019:10:Ed000142.

8. Wells GA, Shea B, O'Connell D, Peterson J, Welch V, Losos M, et al. The Newcastle-Ottawa Scale (NOS) for assessing the quality of nonrandomised studies in meta-analyses. Oxford: Oxford University Press; 2000.

9. Chaimani A, Higgins JP, Mavridis D, Spyridonos P, Salanti G. Graphical tools for network meta-analysis in STATA. PLoS ONE. 2013;8(10):e76654.

10. Catalá-López F, Tobías A, Cameron C, Moher D, Hutton B. Network metaanalysis for comparing treatment effects of multiple interventions: an introduction. Rheumatol Int. 2014;34(11):1489-96.

11. Salanti G, Ades AE, loannidis JP. Graphical methods and numerical summaries for presenting results from multiple-treatment meta-analysis: an overview and tutorial. J Clin Epidemiol. 2011:64(2):163-71.

12. Khalil MH, Rashwan AS. Arthroscopic rotator cuff repair using modified Mason-Allen versus double row suture bridge techniques. Egypt Orthop J. 2018:40:2440-7.

13. Hantes ME, Ono Y, Raoulis VA, Doxariotis N, Venouziou A, Zibis A, et al. Arthroscopic single-row versus double-row suture bridge technique for rotator cuff tears in patients younger than 55 years: a prospective comparative study. Am J Sports Med. 2018:46(1):116-21.

14. Gerhardt C, Hug K, Pauly S, Marnitz T, Scheibel M. Arthroscopic single-row modified Mason-Allen repair versus double-row suture bridge reconstruction for supraspinatus tendon tears: a matched-pair analysis. Am J Sports Med. 2012:40(12):2777-85.

15. Lee KW, Yang DS, Lee GS, Ma CH, Choy WS. Clinical outcomes and repair integrity after arthroscopic full-thickness rotator cuff repair: suture-bridge versus double-row modified Mason-Allen technique. J Shoulder Elbow Surg. 2018;27(11):1953-9.

16. Pennington WT, Gibbons DJ, Bartz BA, Dodd M, Daun J, Klinger J, et al. Comparative analysis of single-row versus double-row repair of rotator cuff tears. Arthrosc J Arthrosc Relat Surg Off Publ Arthrosc Assoc N Am Int Arthrosc Assoc. 2010;26(11):1419-26.

17. Urita A, Funakoshi T, Horie T, Nishida M, Iwasaki N. Difference in vascular patterns between transosseous-equivalent and transosseous rotator cuff repair. I Shoulder Elbow Surg. 2017:26(1):149-56.

18. Mihata T, Watanabe C, Fukunishi K, Ohue M, Tsujimura T, Fujiwara K, et al. Functional and structural outcomes of single-row versus double-row versus combined double-row and suture-bridge repair for rotator cuff tears. Am J Sports Med. 2011;39(10):2091-8.

19. Tudisco C, Bisicchia S, Savarese E, Fiori R, Bartolucci DA, Masala S, et al. Single-row versus double-row arthroscopic rotator cuff repair: clinical and 3 TMR arthrography results. BMC Musculoskelet Disord. 2013;14:43.

20. McCormick F, Gupta A, Bruce B, Harris J, Abrams G, Wilson H, et al. Singlerow, double-row, and transosseous equivalent techniques for isolated supraspinatus tendon tears with minimal atrophy: a retrospective comparative outcome and radiographic analysis at minimum 2-year followup. Int J Shoulder Surg. 2014;8(1):15-20.

21. Carbonel I, Martinez AA, Calvo A, Ripalda J, Herrera A. Single-row versus double-row arthroscopic repair in the treatment of rotator cuff tears: a prospective randomized clinical study. Int Orthop. 2012;36(9):1877-83.

22. Gartsman GM, Drake G, Edwards TB, Elkousy HA, Hammerman SM, O'Connor DP, et al. Ultrasound evaluation of arthroscopic full-thickness supraspinatus rotator cuff repair: single-row versus double-row suture bridge (transosseous equivalent) fixation: results of a prospective, randomized study. J Shoulder Elbow Surg. 2013;22(11):1480-7

23. Yoon JS, Kim SJ, Choi YR, Kim SH, Chun YM. Arthroscopic repair of the isolated subscapularis full-thickness tear: single- versus double-row suturebridge technique. Am J Sports Med. 2019;47(6):1427-33.

24. Burks RT, Crim J, Brown N, Fink B, Greis PE. A prospective randomized clinical trial comparing arthroscopic single- and double-row rotator cuff repair: magnetic resonance imaging and early clinical evaluation. Am J Sports Med. 2009;37(4):674-82. 
25. Ma HL, Chiang ER, Wu HT, Hung SC, Wang ST, Liu CL, et al. Clinical outcome and imaging of arthroscopic single-row and double-row rotator cuff repair: a prospective randomized trial. Arthrosc J Arthrosc Relat Surg Off Publ Arthrosc Assoc N Am Int Arthrosc Assoc. 2012;28(1):16-24.

26. Charousset C, Grimberg J, Duranthon LD, Bellaiche L, Petrover D. Can a double-row anchorage technique improve tendon healing in arthroscopic rotator cuff repair?: A prospective, nonrandomized, comparative study of double-row and single-row anchorage techniques with computed tomographic arthrography tendon healing assessment. Am J Sports Med. 2007;35(8):1247-53.

27. Park JY, Lhee SH, Choi JH, Park HK, Yu JW, Seo JB. Comparison of the clinical outcomes of single- and double-row repairs in rotator cuff tears. Am J Sports Med. 2008;36(7):1310-6.

28. Franceschi F, Ruzzini L, Longo UG, Martina FM, Zobel BB, Maffulli N, et al. Equivalent clinical results of arthroscopic single-row and double-row suture anchor repair for rotator cuff tears: a randomized controlled trial. Am J Sports Med. 2007;35(8):1254-60.

29. Sugaya H, Maeda K, Matsuki K, Moriishi J. Functional and structural outcome after arthroscopic full-thickness rotator cuff repair: single-row versus dualrow fixation. Arthrosc J Arthrosc Relat Surg Off Publ Arthrosc Assoc N Am Int Arthrosc Assoc. 2005;21(11):1307-16

30. Koh KH, Kang KC, Lim TK, Shon MS, Yoo JC. Prospective randomized clinical trial of single- versus double-row suture anchor repair in 2- to 4-cm rotator cuff tears: clinical and magnetic resonance imaging results. Arthrosc J Arthrosc Relat Surg Off Publ Arthrosc Assoc N Am Int Arthrosc Assoc. 2011;27(4):453-62.

31. Grasso A, Milano G, Salvatore M, Falcone G, Deriu L, Fabbriciani C. Single-row versus double-row arthroscopic rotator cuff repair: a prospective randomized clinical study. Arthrosc J Arthrosc Relat Surg Off Publ Arthrosc Assoc N Am Int Arthrosc Assoc. 2009;25(1):4-12.

32. Aydin N, Kocaoglu B, Guven O. Single-row versus double-row arthroscopic rotator cuff repair in small- to medium-sized tears. J Shoulder Elbow Surg. 2010;19(5):722-5.

33. Lapner PL, Sabri E, Rakhra K, McRae S, Leiter J, Bell K, et al. A multicenter randomized controlled trial comparing single-row with double-row fixation in arthroscopic rotator cuff repair. J Bone Jt Surg Am. 2012;94(14):1249-57.

34. Franceschi F, Papalia R, Franceschetti E, Palumbo A, Del Buono A, Paciotti $M$, et al. Double-row repair lowers the retear risk after accelerated rehabilitation. Am J Sports Med. 2016;44(4):948-56.

35. Buess E, Waibl B, Vogel R, Seidner R. A comparative clinical evaluation of arthroscopic single-row versus double-row supraspinatus tendon repair. Acta Orthop Belg. 2009;75(5):588-94

36. Zafra M, Uceda P, Muñoz-Luna F, Muñoz-López RC, Font P. Arthroscopic repair of partial-thickness articular surface rotator cuff tears: single-row transtendon technique versus double-row suture bridge (transosseous equivalent) fixation: results from a prospective randomized study. Arch Orthop Trauma Surg. 2020;140(8):1065-71.

37. Ryu RKN. Arthroscopic transosseous suture repair and single-row anchor fixation for rotator cuff lesions did not differ for pain, function, or rotatorcuff integrity at 15 months. J Bone Jt Surg Am. 2017;99(22):1943.

38. Senna LF, Ramos MRF, Bergamaschi RF. Arthroscopic rotator cuff repair: single-row versus double-row_clinical results after 1 to 4 years. Rev Bras Ortop. 2018;53(4):448-53.

39. Jeong JY, Park KM, Sundar S, Yoo JC. Clinical and radiologic outcome of arthroscopic rotator cuff repair: single-row versus transosseous equivalent repair. J Shoulder Elbow Surg. 2018;27(6):1021-9.

40. Ji JH, Shafi M, Kim WY, Kim YY. Clinical outcomes of arthroscopic single and double row repair in full thickness rotator cuff tears. Indian J Orthop. 2010;44(3):308-13.

41. Wade R, Salgar S. Clinico-radiological evaluation of retear rate in arthroscopic double row versus single row repair technique in full thickness rotator cuff tear. J Orthop. 2017:14(2):313-8.

42. Ide J, Karasugi T, Okamoto N, Taniwaki T, Oka K, Mizuta H. Functional and structural comparisons of the arthroscopic knotless double-row suture bridge and single-row repair for anterosuperior rotator cuff tears. J Shoulder Elbow Surg. 2015;24(10):1544-54.

43. Garofalo R, Calbi R, Castagna A, Cesari E, Budeyri A, Krishnan SG. Is there a difference in clinical outcomes and repair integrity between arthroscopic single-row versus transosseous (anchorless) fixation? A retrospective comparative study. J Orthop Sci Off J Jpn Orthop Assoc. 2018:23(5):770-6.
44. Tashjian RZ, Granger EK, Chalmers PN. Healing rates and functional outcomes after triple-loaded single-row versus transosseous-equivalent double-row rotator cuff tendon repair. Orthop J Sports Med. 2018;6(11):2325967118805365.

45. Pérez-Vicente F, Arroyo A, Serrano P, Candela F, Sánchez A, Calpena R. Prospective randomised clinical trial of single versus double purse-string stapled mucosectomy in the treatment of prolapsed haemorrhoids. Int J Colorectal Dis. 2006;21(1):38-43.

46. Constant CR, Murley AH. A clinical method of functional assessment of the shoulder. Clin Orthop Relat Res. 1987;214:160-4.

47. Boileau P, Brassart N, Watkinson DJ, Carles M, Hatzidakis AM, Krishnan SG. Arthroscopic repair of full-thickness tears of the supraspinatus: does the tendon really heal? J Bone Jt Surg Am. 2005;87(6):1229-40.

48. Parsons BO, Gruson Kl, Chen DD, Harrison AK, Gladstone J, Flatow EL. Does slower rehabilitation after arthroscopic rotator cuff repair lead to long-term stiffness? J Shoulder Elbow Surg. 2010;19(7):1034-9.

49. Bisbinas I, Magnissalis E, Gigis I, Beslikas T, Hatzokos I, Christoforidis I. Rotator cuff repair: a biomechanical ex vivo ovine study. Proc Inst Mech Eng Part H J Eng Med. 2013;227(5):560-70.

50. Sutton A, Ades AE, Cooper N, Abrams K. Use of indirect and mixed treatment comparisons for technology assessment. Pharmacoeconomics. 2008;26(9):753-67.

51. Song F, Altman DG, Glenny AM, Deeks JJ. Validity of indirect comparison for estimating efficacy of competing interventions: empirical evidence from published meta-analyses. BMJ (Clin Res Ed). 2003;326(7387):472.

\section{Publisher's Note}

Springer Nature remains neutral with regard to jurisdictional claims in published maps and institutional affiliations.

Ready to submit your research? Choose BMC and benefit from

- fast, convenient online submission

- thorough peer review by experienced researchers in your field

- rapid publication on acceptance

- support for research data, including large and complex data types

- gold Open Access which fosters wider collaboration and increased citations

- maximum visibility for your research: over $100 \mathrm{M}$ website views per year

At BMC, research is always in progress.

Learn more biomedcentral.com/submissions 